\title{
EFFECTS OF PHYSICAL TRAINING ON THE CARDIOVASCULAR AND RESPIRATORY RESPONSE TO GRADED UPRIGHT EXERCISE IN DISTANCE RUNNERS*
}

\author{
BY \\ B. S. TABAKIN, J. S. HANSON $\dagger$, AND A. M. LEVY \\ From the Cardiopulmonary Laboratory, Department of Medicine, University of Vermont College of Medicine, Mary \\ Fletcher Hospital, Burlington, Vermont, U.S.A.
}

Received April 27, 1964

For the physiologist interested in quantitating changes in circulatory and respiratory variables as a result of physical training, three avenues of approach are open. Each has its own theoretical advantages and defects. First, a group of so-called "normal", sedentary individuals may be compared with a matched group which has undergone a period of organized athletic training. Secondly, studies may be conducted in aspirants for an athletic team prior to and at the peak of their training period. Finally, a group of sedentary subjects may be put through a formalized training programme.

In view of the essential questions related to human physical conditioning and its effects on the circulatory system in man, it is disappointing that so few data have been published relating to upright exercise of varying intensity before and after training in man. Freedman et al. (1955) investigated 3 distance runners by means of cardiac catheterization in the supine position, but only 2 of these were studied before and after training. The effects of training in 12 scullers were reported by Heinecker, Zipf, and Lösch (1960), cardiac output and stroke volume being obtained by indirect methods. Little change in the parameters under study was found. The response of work capacity, blood volume, heart volume, and pulse rate to a non-intensive programme of training has been described by Holmgren et al. (1960). Åstrand (1956) in his review of physical fitness discusses primarily changes in respiratory variables secondary to training, and mentions that "too few" determinations of cardiac output during work exist. A recent publication by Frick, Konttinen, and Sarajas (1963) compares pre- and post-training studies in 14 sedentary young men. However, once again supine data are presented and only one low work load of $400 \mathrm{~kg} . \mathrm{m}$. $/ \mathrm{min}$. employed. An as yet unpublished study by Wang et al. (1965) will discuss the effects of training in sedentary normal subjects (Taylor et al., 1963). Although not concerned with strictly normal subjects, a communication from Holmgren et al. (1957) describes the effects of training in 8 patients with vaso-regulatory asthenia, documenting changes in the electrocardiogram, orthostatic pulse reaction, working capacity, and heart volume. Catheterization studies were also performed in one subject before and after training.

A previous investigation in this laboratory has presented a comparison of hæmodynamic parameters in non-athletic and athletic men (Hanson and Tabakin, 1965), and several other analogous studies have recently appeared (Bevegård, Holmgren, and Jonsson, 1963; Wang et al., 1961 ; Musshoff et al., 1959; Cobb and Johnson, 1963). The present report discusses the effects of a training programme in a group of distance runners, the subjects serving as their own controls in the pre- and

\footnotetext{
* This study was supported by USPHS Research Grant HE-06121-03 of the National Heart Institute.

$\dagger$ Recipient of USPHS Career Reseach Program Award (1-K3-HE-7248) of the National Heart Institute, Bethesda, Maryland.
} 
TABLE I

ANTHROPOMETRIC DATA OF THE 9 SUBJECTS

\begin{tabular}{c|c|c|c|c}
\hline Subject & Age (yr.) & Height (cm.) & Weight (kg.) & BSA (m.2)* \\
\cline { 1 - 2 } 2 & 24 & 170 & 56 & 1.67 \\
2 & 18 & 176 & 70 & 1.86 \\
3 & 20 & 179 & 72 & 1.90 \\
4 & 22 & 171 & 63 & $1 \cdot 74$ \\
5 & 18 & 178 & 73 & 1.91 \\
6 & 17 & 180 & 74 & 1.93 \\
7 & 19 & 180 & 66 & 1.93 \\
8 & 18 & 180 & 67 & 1.77 \\
9 & 18 & 177 & 68 & 1.85 \\
\hline Mean & 19 & & & \\
\hline
\end{tabular}

*Body surface area.

post-training studies. Since this group may represent an athletically-inclined population, a third programme constituting training of previously sedentary, non-athletic men is currently in progress and will subsequently be reported.

\section{SUBJeCTS AND Methods}

Nine members of the University of Vermont 1963 cross-country team formed the subject material for this investigation. At the beginning of the school year in September these college students were studied before engaging in the team's daily training and any competitive meetings. For three months the training consisted of daily setting-up exercises, callisthenics, "wind sprints", and a 4-5 mile cross-country run. Intercollegiate meetings were participated in approximately once a week during this time. Immediately after the final meeting repeat studies were made to assess the effects of training on the physiological parameters under investigation. Although a monetary incentive was provided, its payment was not dependent on a subject's successful completion of any prescribed amount of work, nor was completion of both the pre- and posttraining studies a prerequisite. There were 11 subjects in the original study group who had successful pretraining assessments. Two of these men were excluded from the final results because of incomplete studies in the post-training investigation.

No attempt was made during the runners' training period to regulate diet, smoking habits, or amount of sleep at night. The sole requisite for inclusion in the project was daily participation in the training programme administered by the University Department of Physical Education.

Anthropometric data for the group are given in Table I. Mean age for the nine participants was 19 years and mean body surface area $1.85 \mathrm{sq} . \mathrm{m}$. Though body weight changes did occur during the training period in some subjects, these were never greater than 2 kilograms, individual and group values for body surface area being insignificantly affected.

Detailed methodology has been presented in previous reports (Tabakin et al., 1964; Hanson and Tabakin, 1965). Estimation of cardiac output was made by dye-dilution technique using cardiogreen* and a Waters 250-A densitometer $\dagger$ modified for zero suppression to nullify the effect of background dye build-up during repeated injections. The single-injection, continuous arterial sampling technique was employed. A threepoint calibration curve representing dilutions of $1.5,3.0$, and $6.0 \mathrm{mg} . / 1$. of dye in the subject's blood was made before each study to establish linearity of the densitometer response. Blood pressure recordings were made from the in-dwelling radial arterial needles through Statham P23Db strain gauges. All recordings were made on an Electronics for Medicine 8-channel photographic recorder with rapid developer attachment. Simultaneous collection of expired air permitted calculation of minute volume of ventilation, oxygen utilization, and carbon dioxide elimination. Peripheral vascular resistance was calculated from cardiac output and mean arterial pressure. Left ventricular work and left ventricular stroke work, employing cardiac index and stroke index respectively, were calculated as the product of the appropriate index and the mean arterial pressure in mm. $\mathrm{Hg} \times 13.6 \div 1000$.

* Hynson, Westcott, and Dunning, Baltimore, Maryland.

$\dagger$ Waters Corporation, Rochester, Minnesota. 
TABLE II

Mean Values of Pre- and Post-Training Measurements at Rest and for each Exercise Level

\begin{tabular}{|c|c|c|c|c|c|c|c|c|c|c|c|c|c|c|}
\hline $\begin{array}{c}\text { Exercise } \\
\text { level }\end{array}$ & $\begin{array}{c}\text { Heart } \\
\text { rate } \\
\text { (beats/ } \\
\text { min.) }\end{array}$ & $\begin{array}{l}\text { Cardiac } \\
\text { output } \\
(1 . / \mathrm{min} .)\end{array}$ & $\begin{array}{c}\text { Cardiac } \\
\text { index } \\
(1 . / \mathrm{min} . / \\
\left.\mathrm{m} .{ }^{2}\right)\end{array}$ & $\begin{array}{l}\text { Stroke } \\
\text { volume } \\
\text { (ml.) }\end{array}$ & $\begin{array}{c}\text { Minute } \\
\text { volume } \\
\text { (l./min.) } \\
\text { BTPS }\end{array}$ & $\begin{array}{c}\mathrm{O}_{2} \\
\text { utiliza- } \\
\text { tion. } \\
\text { (ml./ } \\
\text { min.) } \\
\text { STPD }\end{array}$ & $\begin{array}{c}\mathrm{CO}_{2} \\
\text { elimina- } \\
\text { tion } \\
\text { (ml./ } \\
\text { min.) } \\
\text { STPD }\end{array}$ & $\begin{array}{l}\text { Work } \\
\text { load } \\
\text { (kg. } \\
\text { m.j } \\
\text { min.) }\end{array}$ & $\begin{array}{c}\text { Blood } \\
\text { pres- } \\
\text { sure } \\
\text { syst. } \\
\text { (mm. } \\
\text { Hg) }\end{array}$ & $\begin{array}{c}\text { Blood } \\
\text { pres- } \\
\text { sure } \\
\text { diast. } \\
\text { (mm. } \\
\mathbf{H g})\end{array}$ & \begin{tabular}{|c} 
Blood \\
pres- \\
sure \\
mean \\
$(\mathrm{mm}$. \\
$\mathrm{Hg})$
\end{tabular} & $\begin{array}{c}\text { PVR } \\
\text { dynes } \\
\text { (cm.- } \\
\left.\text { sec. }{ }^{-5}\right)\end{array}$ & $\begin{array}{c}\text { LVWI } \\
\text { (kg.m./ } \\
\text { min./m².) }\end{array}$ & $\begin{array}{l}\text { LVSWI } \\
\text { (g./m.2) }\end{array}$ \\
\hline $\begin{array}{c}\text { Recumbent } \\
\text { at rest } \\
\begin{array}{c}\text { Standing } \\
\text { at rest } \\
\text { Level }\end{array} \\
4^{\circ} \\
8^{\circ} \\
12^{\circ} \\
14^{\circ}\end{array}$ & $\begin{array}{lr}\text { Pre } & 68 \\
\text { Post } & 60 \\
\text { Pre } & 89 \\
\text { Post } & 80 \\
\text { Pre } & 96 \\
\text { Post } & 89 \\
\text { Pre } & 103 \\
\text { Post } & 102 \\
\text { Pre } & 127 \\
\text { Post } & 124 \\
\text { Pre } & 148 \\
\text { Post } 143 \\
\text { Pre } & 156 \\
\text { Post } & 150\end{array}$ & $\begin{array}{r}8 \cdot 51 \\
7.03 \\
6.91 \\
6 \cdot 14 \\
13.06 \\
10 \cdot 33 \\
14.95 \\
11 \cdot 58 \\
17.44 \\
17.70 \\
19 \cdot 10 \\
17.59 \\
20.31 \\
20 \cdot 13\end{array}$ & $\begin{array}{r}4 \cdot 61 \\
3 \cdot 79 \\
3 \cdot 68 \\
3 \cdot 22 \\
7 \cdot 02 \\
5 \cdot 57 \\
8 \cdot 08 \\
6 \cdot 26 \\
9 \cdot 45 \\
9 \cdot 72 \\
10 \cdot 39 \\
9 \cdot 55 \\
11 \cdot 08 \\
10 \cdot 90\end{array}$ & $\begin{array}{r}126 \\
118 \\
81 \\
80 \\
140 \\
118 \\
146 \\
115 \\
137 \\
143 \\
132 \\
124 \\
132 \\
135\end{array}$ & $\begin{array}{c}9.26 \\
8.92 \\
12.73 \\
11.66 \\
24.41 \\
23.38 \\
29.66 \\
31.40 \\
43.34 \\
42.50 \\
57.51 \\
56.24 \\
62.24 \\
60.05\end{array}$ & $\begin{array}{r}326 \\
286 \\
395 \\
399 \\
988 \\
993 \\
1365 \\
1406 \\
2005 \\
1997 \\
2596 \\
2573 \\
2748 \\
2740\end{array}$ & $\begin{array}{r}254 \\
230 \\
310 \\
308 \\
746 \\
715 \\
1046 \\
1072 \\
1585 \\
1600 \\
2147 \\
2070 \\
2279 \\
2108\end{array}$ & $\begin{array}{l}= \\
= \\
= \\
\bar{z} \\
383 \\
385 \\
766 \\
771 \\
1148 \\
1156 \\
1329 \\
1338\end{array}$ & $\begin{array}{l}131 \\
125 \\
114 \\
117 \\
136 \\
145 \\
142 \\
142 \\
155 \\
151 \\
157 \\
163 \\
160 \\
160\end{array}$ & $\begin{array}{l}66 \\
62 \\
61 \\
68 \\
64 \\
60 \\
59 \\
58 \\
69 \\
62 \\
74 \\
70 \\
71 \\
75\end{array}$ & $\begin{array}{l}83 \\
80 \\
76 \\
82 \\
87 \\
84 \\
85 \\
82 \\
92 \\
88 \\
99 \\
96 \\
96 \\
98\end{array}$ & $\begin{array}{r}780 \\
910 \\
887 \\
1080 \\
559 \\
651 \\
482 \\
578 \\
418 \\
398 \\
426 \\
459 \\
391 \\
381\end{array}$ & $\begin{array}{r}5 \cdot 20 \\
4 \cdot 12 \\
3 \cdot 80 \\
3 \cdot 59 \\
8 \cdot 31 \\
6 \cdot 36 \\
9 \cdot 34 \\
6 \cdot 98 \\
11 \cdot 82 \\
11 \cdot 63 \\
13 \cdot 99 \\
12 \cdot 47 \\
14 \cdot 47 \\
14 \cdot 53\end{array}$ & $\begin{array}{l}76 \cdot 76 \\
69 \cdot 63 \\
45 \cdot 48 \\
47.95 \\
89 \cdot 92 \\
73 \cdot 11 \\
91 \cdot 32 \\
69 \cdot 14 \\
92 \cdot 59 \\
92 \cdot 15 \\
95 \cdot 59 \\
92 \cdot 70 \\
92 \cdot 70 \\
97 \cdot 29\end{array}$ \\
\hline
\end{tabular}

PVR = Peripheral vascular resistance; LVWI $=$ Left ventricular work index; LVSWI $=$ Left ventricular stroke work index.

All measurements were made with each subject recumbent at rest, standing at rest, walking at 3 miles an hour on the level treadmill and at treadmill elevations of $4^{\circ}, 8^{\circ}, 12^{\circ}$, and $14^{\circ}$. As in previous studies a rest was allowed after each exercise period in order to permit heart rate to return to resting levels before institution of the next work load. This was felt necessary to obviate variations in the "steady state" which are observed over prolonged periods of constant work (Levy, Tabakin, and Hanson, 1961).

Statistical analysis of data was carried out by the IBM 1620 Data Processing system with appropriate programming. Means, standard deviations of the means, regression equations and their standard errors of the estimate, as well as correlation coefficients, were obtained where indicated. Significances of differences were calculated taking into consideration the correlation coefficient for the paired data of this before-and-after type of study.

\section{RESULTS}

As may be appreciated from Table II, significant changes following training in the parameters studied were observed infrequently. Post-training heart rate at rest both recumbent and standing, and also during level treadmill exercise, showed moderate and significant declines. For all higher levels of exercise, heart rate was lower after the training period, but decreases were of minimal degree.

Significant alterations of cardiac output were observed for the level and $4^{\circ}$ treadmill walks, consisting of decreases from the pre-training values. A $1.51 . / \mathrm{min}$. decrement in mean systemic flow was also evident for recumbent rest, but this was statistically insignificant. Pre- and posttraining data were otherwise identical. These relations are mirrored in the data for left ventricular work index which reveal significant reductions after training for the level and $4^{\circ}$ exercise only.

Stroke volume in the post-training studied was significantly reduced for the level and $4^{\circ}$ exercise. Since heart rate decrements for these degrees of work were modest, this reflects primarily the reduction in cardiac output observed. For all other measurements pre- and post-training data were almost identical, mean values varying only 1-8 ml. Left ventricular stroke work index calculations demonstrated changes parallel to those in stroke volume, significant decreases appearing during walking on the level and at $4^{\circ}$.

Considerable increases in mean peripheral vascular resistance were noted following training for both resting and the two lowest exercise grades, but because of wide individual subject differences, statistical significance was absolute only for the level walk. No change in resistance was seen for the $8^{\circ}, 12^{\circ}$, and $14^{\circ}$ exercise.

Systolic, diastolic, and mean arterial blood pressures were very similar for the original and repeat studies. Differences of the means for all levels were without exception statistically insignificant.

Ventilatory variables likewise exhibited no conspicuous changes from pre-training values. 
Minute volume of ventilation, oxygen utilization, and carbon dioxide elimination all showed differences of the means which were entirely within the limits of measurement error. Oxygen ventilatory equivalent, expressed as litres of ventilation per litre of oxygen utilization, was slightly lower after training for the standing resting, level, $8^{\circ}$, and $14^{\circ}$ determinations, but no statistical significance was established.

\section{Discussion}

The most striking conclusion to be reached from the present study is that with two exceptions at lower levels of exercise, no significant differences in the cardio-respiratory variables measured were demonstrable before and after a rigorous training programme. This may well be related to a factor mentioned by Åstrand (1956): "the category of individuals who submit to regular training forms a select group and generally has special qualifications for physical work." However, this cannot be the sole explanation in the present case, since the pre-training values in most instances more closely resemble those of a truly non-athletic group (Tabakin et al., 1964). In fact, the current group of subjects resembles the previously-studied runners (Hanson and Tabakin, 1965) only with regard to heart rate and oxygen utilization.

One of the significant differences observed between pre- and post-training is illustrated in Fig. 1. For the two lowest levels of exercise it is obvious that after training the group responds with a lower cardiac output at a given oxygen utilization. The similarity of this relation to that earlier noted for runners and non-athletes (Hanson and Tabakin, 1965) is clear. Fig. 2 presents these findings in terms of individual values rather than group data, and a regression line for the post-training observations would once again indicate a lower cardiac output for a given oxygen utilization.

These results differ somewhat from those of Freedman et al. (1955) and Frick et al. (1963), both of these investigations reporting no change in cardiac output after training. Although supine subjects were studied in both instances, the lack of post-training variation in cardiac output was documented at work loads and oxygen utilizations closely approximating those

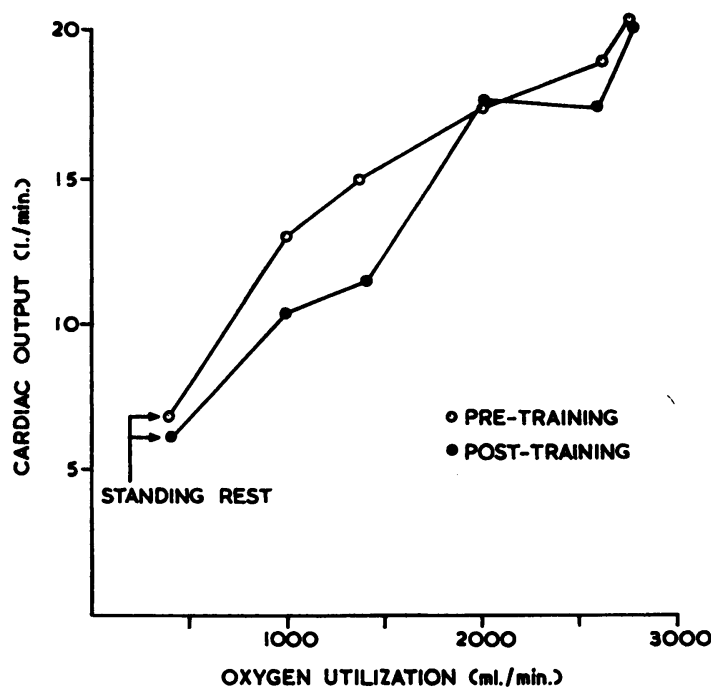

FIG. 1.-Relationship of mean cardiac output to mean oxygen utilization standing at rest and for five grades of treadmill exercise before and after training.

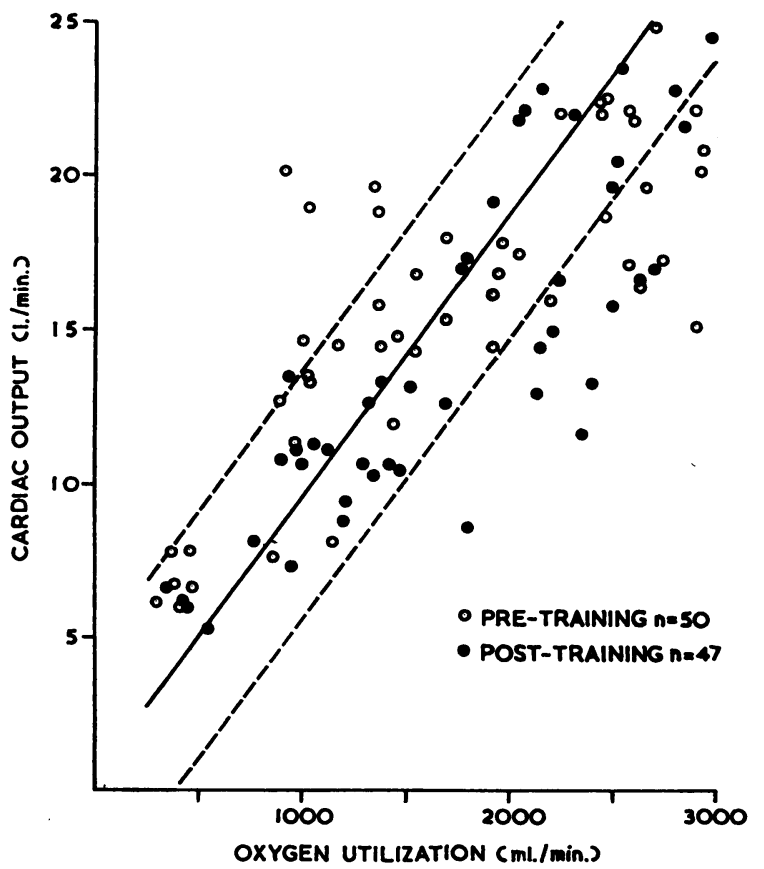

FIG. 2.-Individual values for cardiac output and oxygen utilization. The solid line represents the regression line for normal, non-athletic subjects and the broken lines \pm one standard error of the estimate. Regression equation: $y=0.424+0.0091$ $x, \mathrm{n}=162$ (Hanson and Tabakin, 1965). 
at which the present changes were observed. It is suggested that our lower mean cardiac outputs at these levels may represent an adaptation to a particular grade of work which these athletes performed daily during training. During the daily training runs a speed of 9-10 miles an hour was maintained by the subjects. Neglecting the factors of muscle fatigue and prolonged exercise, this would approximate the amount of work performed in the present study between the level and $8^{\circ}$ exercise grades. This is exactly the range (Fig. 1) where the group differences are most apparent in the untrained and trained states. In contrast, the effects of training on cardiac output in sedentary subjects to be published by Wang et al. (1965) as reported by Taylor et al. (1963) were not marked. Increases of output were found at two sub-maximal exercise levels and a decrease at one level, but all differences before and after training were less than 5 per cent of the group mean.

Almost without exception in the published reports a relative bradycardia has been mentioned as a hallmark of the trained state. Our group exhibited significant post-training decreases in heart rate recumbent and standing at rest, and walking on the level treadmill. For all other work loads mean heart rate following training closely approximated that seen originally. The pre-training heart rates, as previously mentioned, however, characterized this particular group more closely as athletes than non-athletes.

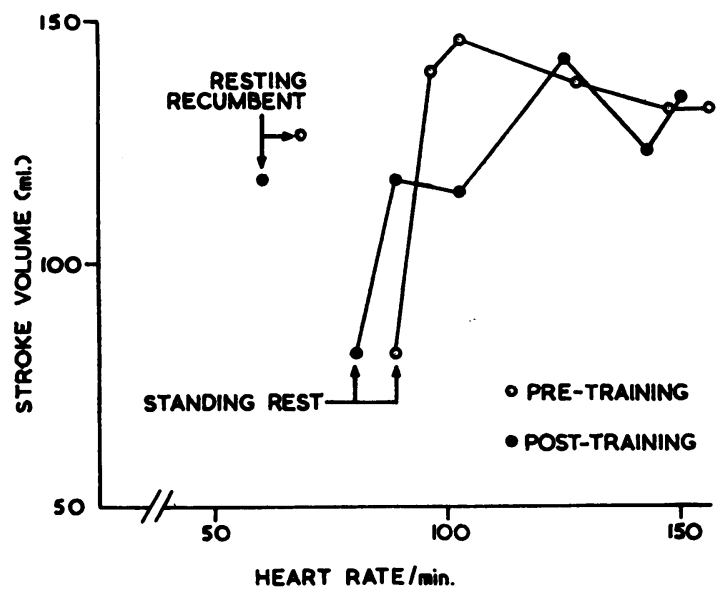

Fig. 3.-Plot of mean stroke volume versus heart rate for standing resting and five exercise levels preand post-training.

As seen in Fig. 3 the relatively minor changes in heart rate but significantly lowered cardiac output in the trained state are related to considerably lower mean stroke volume for the level and $4^{\circ}$ treadmill walks as compared to the untrained state. In the original studies the group's stroke volume response closely parallels that of nonathletic, untrained males (Hanson and Tabakin, 1965), varying little after the onset of exercise. Post-training, however, a relatively low stroke volume plateau is reached at the two lightest work loads, following which the values are again almost identical to pre-training. This once again raises the possibility that an efficient cardiovascular adjustment to an oft-repeated work load has been accomplished, lower left ventricular work index and stroke work index being the objectives attained.

Other indicators of hæmodynamic exercise response considered in this study were unaffected by the training period. Systolic, diastolic, and mean arterial blood pressures were virtually identical before and after training for determinations at all levels, as was peripheral vascular resistance. There has been little indication in published reports that arterial blood pressure differs in athletes and non-athletes or is altered by a period of training. Bevegård et al. (1963) did find higher mean brachial artery pressures at a high work load in 3 of their 8 athletes, but the other 5 followed the regression line for normal subjects.

Respiratory variables under observation were also insignificantly altered by training. Small decrements in carbon dioxide elimination were observed at the $12^{\circ}$ and $14^{\circ}$ exercises, but these post-training differences were in no way comparable with the highly significant discrepancy found between normal subjects and athletes. In reference to the oft-stated theorem that the trained state is associated with an improved ventilatory efficiency and therefore lower ventilatory equivalent for oxygen, we have once again, within the limits of this study, been unable to confirm a significant training effect. Oxygen ventilatory equivalents during exercise decreased at most by 1.0 litre/litre oxygen in the repeat studies. The original equivalents in the range 22-23 litres/litre oxygen also suggest that this particular group had in their "untrained" state already achieved a considerable degree of ventilatory efficiency. 
With the obvious exceptions of cardiac output and stroke volume discussed above, the present investigation has not substantiated significant post-training alterations of several hæmodynamic and respiratory parameters. It is proposed that the isolated variations seen in the mid-exercise range may be related to a work load which was repeated daily for relatively long intervals during the training period. On the basis of the present results we are inclined to agree with Heinecker et al. (1960): "So kann durch die Bestimmung der genannten Grössen nicht mit genügender Sicherheit Auskunft über die körperliche Leistungsfähigkeit eines Untersuchten erlangt werden."*

\section{SUMMARY}

Nine cross-country runners were studied with regard to the effects of a three-month period of rigorous physical training on various circulatory and respiratory parameters. Relatively few differences in these variables were observed before and after training. Decrements in cardiac output in the trained state during submaximal exercise may represent an adaptation to a particular grade of work which the athletes performed daily during training. It is concluded that whereas gross differences between sedentary and athletic subjects are demonstrable in the variables studied, athletes may represent a select group with special qualifications for physical work, and a quantitation of their state of physical training is difficult to assess by these methods.

\section{REFERENCES}

Åstrand, P.-O. (1956). Human physical fitness with special reference to sex and age. Physiol. Rev., $36,307$.

Bevegård, S., Holmgren, A., and Jonsson, B. (1963). Circulatory studies in well trained athletes at rest and during heavy exercise, with special reference to stroke volume and the influence of body position. Acta physiol. scand., 57, 26.

Cobb, L. A., and Johnson, W. P. (1963). Hemodynamic relationships of anærobic metabolism and plasma free fatty acids during prolonged, strenuous exercise in trained and untrained subjects. J. clin. Invest., $42,800$.

Freedman, M. E., Snider, G. L., Brostoff, P., Kimelblot, S., and Katz, L. N. (1955). Effects of training on response of cardiac output to muscular exercise in athletes. J. appl. Physiol., 8, 37.

Frick, M. H., Konttinen, A., and Sarajas, H. S. S. (1963). Effects of physical training on circulation at rest and during exercise. Amer. J. Cardiol., 12, 142.

Hanson, J. S., and Tabakin, B. S. (1965). Comparison of the circulatory response to upright exercise in 25 "normal" men and 9 distance runners. Brit. Heart J., 27, 211.

Heinecker, R., Zipf, K-E., and Lösch, H. W. (1960). Über den Einfluss körperlichen Trainings auf Kreislauf und Atmung. Z. Kreisl.-Forsch., 49, 913.

Holmgren, A., Jonsson, B., Levander, M., Linderholm, H., Mossfeldt, F., Sjöstrand, T., and Ström, G. (1957). Physical training of patients with vasoregulatory asthenia. Acta med. scand., 158, 437.

-, Mossfeldt, F., Sjöstrand, T., and Ström, G. (1960). Effect of training on work capacity, total hemoglobin, blood volume, heart volume and pulse rate in recumbent and upright positions. Acta physiol. scand., $50,72$.

Levy, A. M., Tabakin, B. S., and Hanson, J. S. (1961). Cardiac output in normal men during steady-state exercise utilizing dye-dilution technique. Brit. Heart J., 23, 425.

Musshoff, K., Reindell, H., Steim, H., and König, K. (1959). Die Sauerstoffaufnahme pro Herzschlag (O2-Puls) als Funktion des Schlagvolumens, der arteriovenösen Differenz, des Minutenvolumens und des Herzvolumens. Z. Kreisl.-Forsch., 48, 255.

Tabakin, B. S., Hanson, J. S., Merriam, T. W., and Caldwell, E. J. (1964). Hemodynamic response of normal men to graded treadmill exercise. J. appl. Physiol., 19, 457.

Taylor, H. L., Wang, Y., Rowell, L., and Blomqvist, G. (1963). The standardization and interpretation of submaximal and maximal tests of working capacity. Pediatrics, 32, 703.

Wang, Y., Rowell, L. B., Blomqvist, G., and Taylor, H. L. (1965). The effects of a conditioning program on the cardiovascular function in exercise of sedentary college males. J. appl. Physiol. To be published.

- , Shepherd, J. T., Marshall, R. J., Rowell, L., and Taylor, H. L. (1961). Cardiac response to exercise in unconditioned young men and in athletes (abstract). Circulation, 24, 1064.

* "Therefore, information delineating the physical capabilities of a subject cannot be achieved with sufficient certainty through quantitating the variables discussed." 